\title{
The Granger Causality Relationship between Foreign Direct Investment (FDI) and Economic Development in the State of Qatar
}

\author{
Mohanad Fayez Alkhasawneh* \\ Mathematics, Statistics Physics Department, Qatar University, Doha 2713, Qatar
}

Received: 7 Jan. 2013, Revised: 10 May. 2013, Accepted: 11 May. 2013

Published online: 1 Sep. 2013

\begin{abstract}
In this study, we investigate the causality relationship between the inflows of foreign direct investment and economic development as measured by Gross Domestic Product (GDP) per capita in the State of Qatar during the period 1970 - 2010. It also investigates the direction of the relation between the two variables using several tests: Augmented Dickey-Fuller (ADF), Johansen cointegration and Granger Causality tests. Robust empirical findings drawn from the Johansen cointegration analysis suggest the existence of such long-run equilibrium relationship between FDI and GDP. Furthermore, causality test indicates that there is a bidirectional causality on the FDI-GDP relationship for one, two and three year lags that imply, strongly indicating that foreign capital penetration Granger-causes economic growth in Qatar. The test results show that foreign direct investment in the short-run is affected mainly by gross domestic product and government spending which implies that the government should continue its efforts to create the economic environment which is attractive to foreign direct investment. The findings confirm the strong and positive relationship between economic growth of Qatar and FDI inflows.
\end{abstract}

Keywords: Economic of Qatar, Foreign Direct Investment, Gross Domestic Product, Cointegration, and Granger Causality

\section{Introduction}

Qatar is relatively a small country in size occupying around $11,437 \mathrm{~km}$ square. It has a population of 1.68 million. More than $85 \%$ of Qatar population lives within $20 \mathrm{~km}$ radius of Doha. In Qatar, there are around 100 different nationalities working in different economic sectors. The State of Qatar has witnessed a rapid economic growth over the last decade. The national economic policy focuses on increasing private and foreign investment in non-energy sectors given that oil and gas contribute for around $50 \%$ of GDP and $85 \%$ of export revenues. Qatar has unemployment rate of $0.5 \%$ (2009). Qatar is going to host the compact FIFA World Cup for 2022. Qatar would be the first nation in the Middle East to stage the FIFA World Cup in history. Qatar has already staged other major international sport events for instant Asian Games in 2006 and Asian Football Cup in 2011 (Qatar Bid Evaluation Report for 2022 FIFA World Cup).

In Qatar, Gross Domestic Product, GDP growth has an increasing pattern during the impressive economic development the country witnessed through the last decade. In 2010, GDP of Qatar reached around QR 470 billion. It recorded a nominal growth of $30.8 \%$ and CPI inflation was $-2.4 \%$. In the same year, the growth was evenly distributed between Oil and Gas and the Non-oil and Gas Sectors. The banking system in Qatar maintained adequate liquidity and comfortable capital position along with high margins during 2010. There were 43 listed companies across four major segments registered in Qatar exchange by the end of Dec 2010. [9].

Due to financial stability the State of Qatar witnessed, foreign direct investment is expected to be boosted due to increasing attraction from foreign investors by which greater economic diversification is expected. The foreign trade conditions were improved during 2010 with high growth in exports and a high surplus. The foreign trade exhibited a growth of $30.1 \%$, i.e. QR 346.87 billion. On the other

\footnotetext{
*Corresponding author e-mail: alkhasawneh@qu.edu.qa
} 


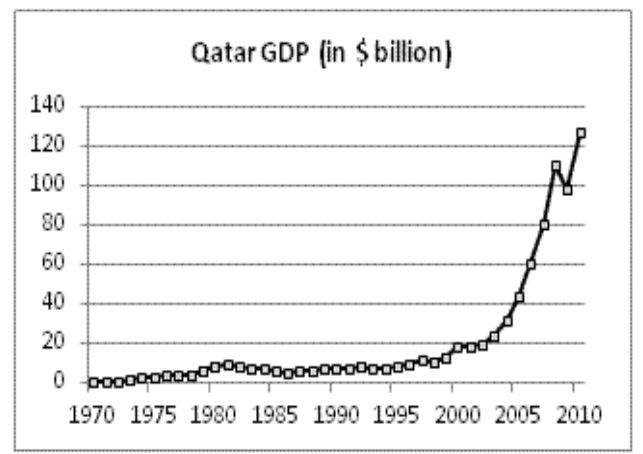

Fig. 1: Qatar GDP (1970 to 210).

hand, the indicator of openness declined comparing to 2009. Export of goods had a upward growth of $49.2 \%$, i.e. QR 262.28 billion and downward growth of $6.7 \%$ of imported goods stood at QR 84.59 billion comparing to 2009. Exports had $75.6 \%$ of foreign trade with an increase of $9.6 \%$ comparing to 2009.

Qatar's imports are divided into four geographical groups: European, Asian, Arab and American counties. European counties take the largest share of import of goods forming 34\% of overall imports coming from all countries, i.e. QR 28.75 billion. Asian import of goods take the second share with $30.4 \%$ (i.e. QR 25.75 billion), imports from Arab countries take a share of $18.4 \%$ (QR 15.55 billion) and American countries have a share of $15.1 \%$ (QR 12.75 billion) of total imports [9].

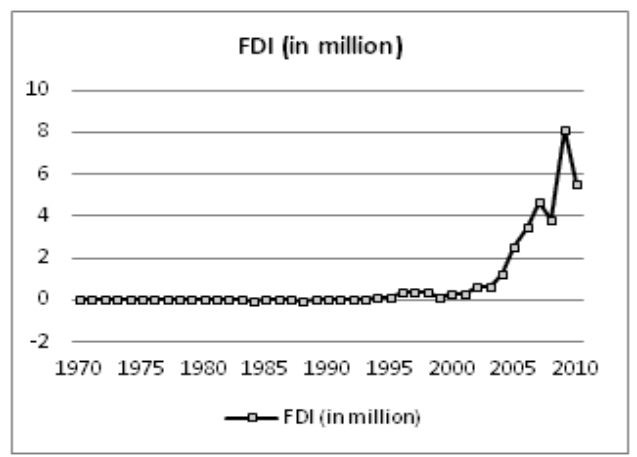

Fig. 2: Qatar FDI (1970 to 210).

The objective of this paper is to study the presence of interdependence between GDP and FDI for the State of Qatar. Qatar's government has targeted foreign direct investment as a crucial element of its 2030 strategy for economic growth and development. Foreign direct investment enhances the rate of technology transfer. Furthermore, it better integrates the country into the world economy and gives access to global markets. The flow of FDI to developing countries has shifted from market-seeking and resource-seeking FDI to more efficiency-seeking FDI. However, the inflow of foreign direct investment to Qatar could be characterized as resource-seeking due to the fact that the greatest share of foreign direct investment is in the internationally traded petroleum and liquefied natural gas (LNG) products. Hence the growth rate in exports of oil and LNG should be positively correlated with FDI. The size of the host country is an important factor that attracts FDI, especially flows to developing countries. In most studies market size is approximated GDP, population, GDP per capita and GDP growth rate. For the purpose of this study we will use GDP. This direction of causality supports the growth-driven FDI hypothesis, which stresses that the market size of the host country, represented by GDP, rises with economic growth, and hence, can attract foreign investment. To capture the impact of globalization on FDI, the degree of openness is introduced as an explanatory variable approximated by the ratio of exports and imports to GDP. Moreover, the existence of advanced infrastructure makes the country more attractive to foreign investors.

Relevant Literature Review will be introduced in Section 2. The rest of the paper is organized as follows. In Section 3 we present our methodology in this paper. The Analysis and Results of the study are in Section 4. We conclude our paper in Section 5.

\section{Literature Review}

During the last decade a number of interesting studies of the role of foreign direct investment in stimulating economic growth has appeared. A study, done by Andreas G. Georgantopoulos and Anastasios D. Tsamis, on "The Causal Links between FDI and Economic Development: Evidence from Greece" in 2011 [3], aimed to investigate the causal relationship between GDP per capital and foreign direct investment in Greece during the period 1970 - 2009. The study concluded that there is existence of a long-run equilibrium relationship and uni-directional causality running from GDP to FDI. The same authors of previous study had conducted similar study, on "The Triangular Causal Links between Economic Development, FDI and Exports: Evidence from Turkey" in 2011 [4], aimed to investigate the causal relationship foreign capital and foreign trade for Turkey during the period 1970 - 2009. Similarly, the study concluded that there was long-run relationship and there was uni-directional from FDI to GDP, exports to GDP, and exports to FDI.

Moreover, another study done by Frimpong Joseph Magnus and Oteng-Abayie Eric Fosu, on "Bivariate Causality Analysis between FDI Inflows and Economic Growth in Ghana" in 2008 [6]. The objective for their study was to explore the causal link between FDI and GDP growth for Ghana during the period 1970-2002. The study concluded that no causality between FDI and growth for the total sample period and the pre-SAP 
period; However, FDI caused GDP during the post-SAP period. Abdus Samad [1] had investigated the causal link between FDI and Economic Growth of ten counties of Latin America, on his study of "FDI and Economic Growth: Evidence from Latin America". The study concluded that there were five countries, named (Argentina, Bolivia, Brazil, Columbia, El- Salvado), have long-run relationships and uni-directional, and bi-directional causality between GDP growth and FDI; on the other hand, four other countries, named (Chile, Ecuador, Guatemala, Mexico), have short-run relationship and mixed causal link between GDP growth and FDI.

Furthermore, a group of researchers, Muhammad Irfan Javaid Attari, Dr. Yasir Kamal, and Sumayya Nasim Attari [7], conducted a study of "The Causal Link between Foreign Direct Investment and Economic Growth in Pakistan Economy". The study aimed to examine the relationship between Foreign Direct Investment and Economic Growth of Pakistan during the period between 1981 and 2009. The study concluded that there is long-run relationship between the macroeconomic variables and there is bi-direction causality for GDP and exports, and FDI and exports. Chakraborty and Basu (2002) [5] examine the causality between FDI and output growth in India. Utilizing annual data from 1974-1996, they find that the real GDP in India is not Granger-caused by FDI and the causality runs more from real GDP to FDI.

Moreover, there was a study, entitled "The Attractiveness of Qatar to Foreign Direct Investment, 1980-2002", conducted by Shotar M, Manhal [8], in which the researcher aimed to the factors that determine the inflow of FDI to Qatar and the attractiveness of Qatar to FDI. He concluded that there were short-run in FDI and affected by government spending and GDP.

Finally, Mahmoud Al-Iriani and Fatima Al-Shami [2] conducted a study in 2007 testing for the relationship between FDI and growth in the six countries comprising the Gulf Cooperation and using heterogeneous panel analysis methods indicate a bi-directional causality. Their results support the endogenous growth hypothesis for this group of countries.

\section{Methodology}

The objective of this study is to empirically establish the impact FDI has on economic growth of Qatar and explore if bi-directional causality exists. To fulfil the study objective, different approaches are used. The proposed empirical technique is time-series analysis. The model has two variables - growth rate of real GDP and real FDI inflows as a percentage of GDP. The purpose is to see whether there exists a long-run stable relationship between the two variables. Hence cointegration exercise is conducted. But before doing the cointegration test, the following intermediate steps need to be carried out: scatter-plots of the above variables for possible relationship; Pearson's correlation (coefficient $r$ ) while testing for its assumptions - absence of outliers; absence of non-homogenous groups; normality and linearity. Further, Jarque-Bera normality tests are also performed. These tests are based on sample skewness and kurtosis. This is followed by tests for autocorrelation (Ljung-Box portmanteau tests) and heteroskedasticity. The last intermediate step is test for unit root in time-series of the variables using Phillips and Perron (1988) tests. If the series show presence of unit root (ie. Non-stationary but integrated of order 1), then cointegration becomes an econometric and conceptual possibility.

Furthermore, Augmented Dickey-Fuller (ADF) test has been used to test unit roots of FDI and GDP time series. This can be done by taking the first difference for series of lag one as following formula:

$\Delta y_{t}=\alpha_{1} \cdot y_{i t-1}+\sum_{i=1}^{p_{i}} \beta_{i j} \cdot \Delta_{i t-j}+x_{i t} \delta+\varepsilon_{t}$

Finally, Johansen's test of cointegration is conducted to find out whether a long-run relationship exists between FDI and GDP. The Johansen's technique is based on maximum likelihood estimation. The Granger causality test was used to explore the existence of a bi-directional causality between GDP and FDI for Qatar for the proposed study period. If FDI can help to forecast GDP, then we can say that FDI Granger-causes GDP. However, if FDI causes GDP and not versa vice, then we say there is unidirectional causality exists from FDI and GDP. The Granger approach answers the question whether GDP causes FDI by finding how much of the current value of GDP can be explained by past values of GDP and lagged values of FDI. Thus, to test for causality between GDP and FDI, we shall estimate the following regression equations:

$$
\begin{gathered}
G D P_{t}=\gamma+\sum_{i=1}^{k} \alpha_{i} \cdot G D P_{t-i}+\sum_{i=1}^{k} \beta_{i} \cdot F D I_{t-i}+\mu_{t} \\
F D I_{t}=\phi+\sum_{i=1}^{k} \delta_{i} \cdot G D P_{t-i}+\sum_{i=1}^{k} \lambda_{i} \cdot F D I_{t-i}+\eta_{t}
\end{gathered}
$$

where $G D P_{t}$ and $F D I_{t}$ are stationary time series sequences, $\mu_{t}$ and $\eta_{t}$ are the respective intercepts, and are white noise error terms, and $\mathrm{k}$ is the maximum lag length used in each time series (decided by Akaike Information Criterion (AIC) or Bayesian Information Criterion (BIC)). FDI is said to Granger cause GDP if the $\beta_{i}$ coefficients are jointly significantly different from zero.Similarly, GDP is said to Granger cause FDI if the $\delta_{i}$ coefficients are jointly significantly different from zero

\section{Analysis and Results}

The study uses data that consists of annual records of FDI and GDP of the State of Qatar from 1970 to 2010. This 
period is important for a variety of reasons and includes certain major local, regional and global events that affected Qatar- inflows of FDI and domestic economic reforms. FDI data obtained from the World Bank database and GDP data obtained from the Qatar Statistics Authority (QSA). FDI recorded as US dollar; however, GDP recorded as Qatari Riyal. For converting GDP to US dollar, currency rate of 3.65 was used. Table 1 reports the descriptive statistics for the sample of the two variables. Overall, calculations indicate that GDP and FDI are not normally distributed and skewed.

Table 1: Descriptive statistics for GDP and FDI

\begin{tabular}{||r||r|r||}
\hline \hline Measures & FDI (in billion) & GDP (in billion) \\
\hline \hline Mean & 0.799826 & 19.69917 \\
Median & 0.027340 & 7.374451 \\
Maximum & 8.124736 & 126.9841 \\
Minimum & -0.020630 & 0.301791 \\
Std. Dev. & 1.789616 & 30.84778 \\
Skewness & 2.632599 & 2.322828 \\
Kurtosis & 9.401439 & 7.292541 \\
Jarque-Bera & 117.3637 & 68.34704 \\
Probability & 0.000000 & 0.000000 \\
\hline \hline
\end{tabular}

Table 2: Augmented Dickey-Fuller Unit Root Test for Log(FDI).

\begin{tabular}{|c|c|c|c|c|c|c|}
\hline & \multicolumn{2}{|c|}{ Test1 } & \multicolumn{2}{|c|}{ Test2 } & \multicolumn{2}{|c|}{ Test3 } \\
\hline & Levels & $D^{3}$ & Levels & $D^{3}$ & Levels & $D^{3}$ \\
\hline $\begin{array}{l}\text { The first } \\
\text { autoco- } \\
\text { rrelation }\end{array}$ & $0.01^{1}$ & 0.104 & 0.040 & 0.955 & 0.003 & 0.03 \\
\hline Intercept & 0.69 & 0.362 & 0.369 & 0.181 & - & - \\
\hline Trend & $--^{2}$ & - & 0.267 & 0.102 & - & - \\
\hline \multicolumn{7}{|c|}{$\begin{array}{ll}{ }^{1} P-\text { value. } & \text { Test } 1=\text { with } \text { intercept }\end{array}$} \\
\hline \multicolumn{7}{|c|}{${ }^{2}$ Not in the equation. Test $2=$ with intercept and trend } \\
\hline
\end{tabular}

Table 2 shows the outcomes of the Augmented Dickey-Fuller unit root test in levels and in first differences of $\log (\mathrm{FDI})$ in terms with an intercept, with an intercept and trend and with no intercept or trend and similarly to Table 3 for $\log (\mathrm{GDP})$. This test is one of require steps to identify the existence of unit root and
Table 3: Unit Root Test for $\log (\mathrm{GDP})$.

\begin{tabular}{|c|c|c|c|c|c|c|}
\hline & \multicolumn{2}{|c|}{ Test1 } & \multicolumn{2}{|c|}{ Test2 } & \multicolumn{2}{|c|}{ Test3 } \\
\hline & Levels & $D^{3}$ & Levels & $D^{3}$ & Levels & $D^{3}$ \\
\hline $\begin{array}{l}\text { The first } \\
\text { autoco- } \\
\text { rrelation }\end{array}$ & 0.018 & 0.174 & 0.160 & 0.000 & 0.002 & 0.39 \\
\hline Intercept & 0.590 & 0.258 & 0.493 & 0.113 & - & - \\
\hline Trend & - & - & 0.048 & 0.003 & - & - \\
\hline $\begin{array}{l}{ }^{1} \text { P-value. } \\
{ }^{2} \text { Not in } \\
{ }^{3} 1^{s t} \text { Diffe }\end{array}$ & $\begin{array}{l}\text { the equ } \\
\text { ences }\end{array}$ & $\begin{array}{l}\text { Test } \\
\text { on. } \\
\text { Test. }\end{array}$ & $\begin{array}{l}=\text { with } \\
\text { st } 2=\mathrm{w} \\
=\text { with }\end{array}$ & $\begin{array}{l}\text { intercept } \\
\text { th interc } \\
\text { no interc }\end{array}$ & $\begin{array}{ll}\text { ept } & \text { and } \\
\text { ept } & \text { or }\end{array}$ & $\begin{array}{l}\text { trend } \\
\text { trend }\end{array}$ \\
\hline
\end{tabular}

Table 4: Johansen Cointegration Test Results.

\begin{tabular}{|c|c|c|c|c|c|c|}
\hline \multirow[b]{2}{*}{$\begin{array}{c}\text { Null } \\
\text { Hypothesis }\end{array}$} & \multicolumn{3}{|c|}{ Trace } & \multicolumn{3}{|c|}{ Maximum Eigenvalue } \\
\hline & $T^{0}$ & $5 \%{ }^{1}$ & $P^{4}$ & $M E S^{3}$ & $5 \%^{1}$ & $P^{4}$ \\
\hline$r^{2}=0$ & 18.29 & 15.5 & 0.019 & 14.61 & 14.27 & 0.044 \\
\hline$r \leq 0$ & 3.685 & 3.85 & 0.055 & 3.685 & 3.84 & 0.055 \\
\hline $\begin{array}{l}{ }^{0} \text { Trace Stat } \\
{ }^{3} \text { Maximum } \\
{ }^{4} \text { P-value. }\end{array}$ & $\begin{array}{l}\text { istic. } \\
\text { Eigenv }\end{array}$ & $\begin{array}{l}{ }^{1} 5 \% \\
\text { ue } \mathrm{St}\end{array}$ & $\begin{array}{l}\text { ritical } \\
\text { tistic. }\end{array}$ & Value. & & \\
\hline
\end{tabular}

Table 5: Granger Causality Test Results.

\begin{tabular}{|c|c|c|c|c|c|}
\hline Null Hypothesis & & Lag1 & Lag 2 & Lag 3 & Lag 4 \\
\hline \multirow{2}{*}{ FDI does not Granger-cause GDP } & F-Statistics & 24.035 & 30.071 & 14.476 & 13.503 \\
\cline { 2 - 6 } & P-value & 0.0001 & $9 . \mathrm{E}-06$ & 0.0004 & 0.001 \\
\hline \multirow{2}{*}{ GDP does not Granger-cause FDI } & F-Statistics & 79.931 & 7.5317 & 5.0165 & 1.7359 \\
\cline { 2 - 6 } & P-value & $8 . \mathrm{E}-08$ & 0.0060 & 0.0197 & 0.2348 \\
\hline
\end{tabular}

have been performed under 5\% significant level. According to Table 2, null hypothesis cannot reject in first differences for terms with an intercept, and with an intercept and trend, which means that FDI is no stationary. In addition, Table 3 shows the GDP is stationary in levels in terms with an intercept, and with no 
intercept or trend and in first differences in term with an intercept and trend. So, both variables are not integrated in any order.

Table 4 Shows the outcomes of Johansen cointegration test among the data sets, were both maximum eigenvalue and trace test reject the null hypothesis of no cointegration at $5 \%$ significance level according to critical value estimates. Therefore, the number of statistically significant cointegration vectors is equal to one.

Finally, after determining the variables are cointegrated, we go head to analysis the causal links between the variables using the Granger-causality test and testing the p-value of F-statistic used. Table 5 shows the outcomes of Granger-causality tests, were the null hypothesis of "FDI does not Granger-cause GDP" is strongly rejected at $5 \%$ significance level for the tested 1 , 2, 3, and 4 year lags. However, the null hypothesis of "GDP does not Granger-cause FDI" is strongly rejected t $5 \%$ significance level for the tested 1, 2, and 3 year lags.

\section{Conclusion}

This paper intends to examine whether FDI does play an important role in economic growth of Qatar. The results can form a basis of ongoing emphasis of Qatar government on promoting foreign investment. The test results show that foreign direct investment in the short-run is affected mainly by gross domestic product and government spending which implies that the government should continue its efforts to create the economic environment which is attractive to foreign direct investment. The findings confirm the strong and positive relationship between economic growth of Qatar and FDI inflows. Furthermore, Granger causality test indicates that there is a bi-directional causality on the FDI-GDP relationship for one, two and three year lags that imply, strongly indicating that foreign capital penetration Granger-causes economic growth in Qatar.

\section{References}

[1] Abdus Samad, FDI and Economic Growth: Evidence from Latin America \& The 14th International Business Research Conference, Dubai, 28-20 (2011).

[2] M. Al-Iriani and F. M. Al-Shamsi, Foreign Direct Investment and Economic Growth in the GCC Countries A Causality Investigation Using Heterogeneous Panel Analysis, Discussion Papers, International Research Journal of Finance and Economics, (2009).

[3] A. G. Georgantopoulos and A. D. Tsamis, The Causal Links between FDI and Economic Development: Evidence from Greece. Greece, EuroJournals Publishing, (2011).

[4] A. G. Georgantopoulos and A. D. Tsamis, The Triangular Causal Links between Economic Development, FDI and Exports: Evidence from Turkey, Middle Eastern Finance and Economics, (2011).
[5] C. Chakraborty and P. Basu, Foreign direct investment and growth in India, a cointegration approach, Applied Economics, 34, 1061-1073 (2002).

[6] J. M. Frimpong, and Oteng-Abayie, E. F., Bivariate causality analysis between FDI inflows and economic growth in Ghana,International Research Journal of Finance and Economics, 1450-2887 (2008).

[7] M. I. J. Attari, Y. Kamal, S. N. Attari, The Causal Link between Foreign Direct Investment (Fdi) and Economic Growth in Pakistan Economy, The Journal of Commerce, 3, 61-68 (2011).

[8] Shotar M. Manhal, The Attractiveness of Qatar to Foreign Direct Investment, 1980-2002, Applied Econometrics and International Development, 5, 117-132 (2005)

[9] The Thirty Fourth Annual Report, Qatar Central Bank, Qatar, (2010)

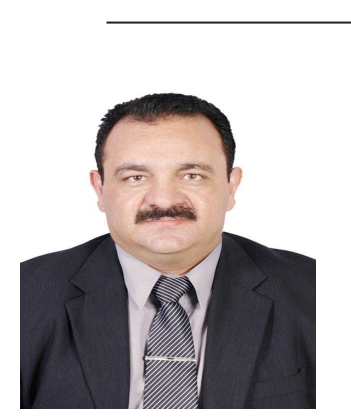

Mohanad Alkhasawneh is a graduate of Yarmouk University. He obtained his Doctorate Degree in Statistics from the University of Windsor in Canada. He has accomplished Advanced Statistical Modeling with over 13 years of total experience in the area of application of Statistical tools and Training. He is the teaching Award winner over all course taught in 2008 and 2009 terms at the University of Windsor in Canada. He has been a Senior Statistician at the Hi-Tech Computer Systems center since 2007. His teaching experience including teaching at Yarmouk University in Jordan and the University of Windsor in Canada. He is currently a faculty member in the Statistics Program at Qatar University. Dr. Alkhasawneh has been an invited speaker of number of conferences and has published several articles in reputed international journals. $\mathrm{He}$ is an Associate Editor of the Research Journal of Mathematics and Statistics and editorial board member and reviewer for several international journals. His recent work has focused on studies of Sampling techniques, generalized linear models and applying survey methods to studies of road safety and medical care. 